\title{
Evaluation of the oral immunogenicity of $M$ cell-targeted tetravalent EDIII antigen for development of plant-based edible vaccine against dengue infection
}

\author{
Byeong-Young $\mathrm{Kim}^{2} \cdot$ Mi-Young $\mathrm{Kim}^{1}[$
}

Received: 8 October 2018 / Accepted: 20 December 2018 / Published online: 2 January 2019

C) Springer Nature B.V. 2019

\begin{abstract}
Four serotypes of the dengue virus that can cause severe disease in humans greatly increases the complexity of vaccine development. In this study, we evaluated an 'all-in-one' tetravalent dengue vaccine candidate as an alternative to the classical four viruses 'cocktail' vaccination approach. A single polypeptide chain of the tetra-EDIII comprising all four serotypes fused to the M-cell target ligand peptide (tEDIII-Co1) was constructed and expressed using a rice expression system under the control of a strong inducible promoter (rice amylase 3D: Ramy3D) and rice 3' untranslated region (UTR). The $t E D I I I-$ Col was constructed using wild type or plant codon optimized gene sequence to compare the expression levels. The codon optimized gene combined with ER-localization showed higher and more stable expression than codon-optimization alone or the wild type. To test the oral immunogenicity of this construct, the transgenic rice cells containing $100 \mu \mathrm{g}$ of tEDIII-Co1 were fed to mice and the antigen specific IgG and IgA antibodies analysed in sera or fecal extracts. The tEDIII fused to Co1 induced strong antibody responses in the absence of any adjuvants. We observed the strongest antigen-specific $\mathrm{B}$ and $\mathrm{T}$ cell responses in animals immunized with tEDIII-Co1. Taken together, this simple tetravalent EDIII-based fusion protein with the $\mathrm{M}$ cell ligand could has potential as an alternative dengue vaccine strategy against all four serotypes.
\end{abstract}

Keywords Oral immunogenicity $\cdot$ Tetravalent vaccine $\cdot$ Dengue $\cdot$ Transgenic rice $\cdot$ M cell ligand

\section{Introduction}

Mosquito-borne diseases caused by viruses (Dengue, Chikungunya, Yellow fever and Zika fever), parasites (malaria, filariasis and dirofilariasis) or bacteria (tularemia) create a

Communicated by Silvia Moreno.

A single tetravalent dengue antigen polypeptide fused to M-cell 1 target ligand (tEDIIICo1) was expressed in transgenic rice cells. ER targeting (SEKDEL) was shown to confer superior stability compared to the secreted protein. Orally administered tEDIIICo1 induced both systemic IgG and mucosal IgA antibodies while circumventing tolerance, thus suggesting that this could be a promising oral immunisation approach.

Mi-Young Kim

mkim@jbnu.ac.kr

1 Department of Molecular Biology, Chonbuk National University, Jeonju, Republic of Korea

2 Department of Bioactive Material Sciences, Chonbuk National University, Jeonju, Republic of Korea big economic burden worldwide. In particular, dengue infection is estimated to affect 390 million people per year, in some cases leading to hospitalization due to severity of the diseases and various complications (Bhatt et al. 2013). Furthermore, 3.9 billion people across 128 countries are at risk of dengue infection (Brady et al. 2012). Member states in three WHO regions declared increasing infection rates (from 2.2 million in 2010 to 3.2 million in 2015) (http://www. who.int/news-room/fact-sheets/detail/dengue-and-sever e-dengue). An efficient vaccine to reduce the infection risk is urgently required while the complexity of the interactions between the host, vector and the virus makes it extremely difficult to control and manage this disease by other means.

So far, Dengvaxia ${ }^{\circledR}$ (also referred to as CYD-TDV, developed by Sanofi Pasteur) is the only approved vaccine and is licensed in 19 countries for use in 9-45 year olds. It confers reduction in severe dengue by $93 \%$ and dengue hospitalizations by $82 \%$ (Hadinegoro et al. 2015). However, its overall efficacy in preventing dengue infection is unsatisfactorily low and it is not recommended by WHO for children under the age of nine. Therefore, new efforts are needed to develop 
an alternative or additional vaccine. Currently, two leading vaccine candidates (TV003/TV005 and TDV developed by NIH/NIAID/Butantan Institute and Inviragen/Takeda, respectively) based on live attenuated chimeric tetravalent formulation are being evaluated in large Phase 3 trials, while other candidates, including inactivated whole virus (TDEN), subunit (V180), and DNA (D1ME100) vaccine candidates are in various stages of Phase I-II trials (Pang and Loh 2017).

Traditional vaccines are mostly based on live attenuated organisms such as measles, mumps, rubella (MMR combined vaccine); varicella (chickenpox); influenza (nasal spray); rotavirus; yellow fever; smallpox etc. Also, inactivated/killed organisms (polio, hepatitis A, rabies) and toxoid vaccines (diphtheria, tetanus) are available. However, those types of vaccines generally have complex safety and storage requirements and there are issues with cost-effectiveness (Lee et al. 2012; Minor 2015). In contrast, subunit vaccines using only a part of the disease-causing virus could overcome both these concerns. Therefore, if they can be made to effectively stimulate the immune system they would be a very safe method of immunization for everyone, regardless of their health status. Nevertheless, subunit vaccines are less successful owing to short-lasting immunity against disease and requiring repeat administrations over specified periods. To increase their effectiveness, subunit vaccines are often engineered alongside various carriers or combined with adjuvants. Here, we genetically engineered a fusion protein that links the dengue antigen with a mucosal adjuvant and evaluated its potential as an oral vaccine in mice.

An ideal dengue vaccine should be safe, cheap and easily administered to young children in low-income countries such as South-East Asia and the Western Pacific regions (Mangold and Reynolds 2013) that show increasing incidence of the disease in the younger age group (Rodriguez-Barraquer et al. 2011). Some of these advantages could be realized by generating subunit vaccines in genetically modified plants (Daniell 2006) which have been shown to have a significant potential by many research groups (Chan and Daniell 2015; Huy and Kim 2017; Kim et al. 2016, 2015). For over 20 years, plant molecular engineering has been progressing to increase the yield of recombinant proteins, which is now comparable to other expression systems including the animal or insect cell cultures. The successful examples include $40 \%$ of TSP for HIV-1 antigen via a chloroplast expression (Gonzalez-Rabade et al. 2011); $3.7 \mathrm{mg} / \mathrm{g}$ fresh weight of GFP by transient expression using a double terminator (Yamamoto et al. 2018) and $150 \mu \mathrm{g} / \mathrm{L}$ of hGM-CSF using a Ramy3D expression system (Shin et al. 2003) - all of which proved to be high enough amounts to test their potential applications. Furthermore, plant-based vaccine candidates for human and animal diseases such as diarrhea caused by Norwalk virus, enterotoxigenic Escherichia coli (ETEC); Tuberculosis caused by Mycobacterium tuberculosis; Gaucher disease caused by Taliglucerase alfa; Foot and mouth disease caused by foot and mouth disease virus (FMDV), have all been generated and evaluated in experimental models of infection (Chan and Daniell 2015). Likewise, many recombinant anti-cancer vaccines including tumor-associated colorectal cancer antigen, prostatic acid phosphatase (PAP) antigen, human papilloma virus $16 \mathrm{~L} 1 / \mathrm{L} 2$ chimeras and the NonHodgkin's lymphoma (NHL) have also produced (Lee and Ko 2017) and some have advanced to or completed phases II and III trials (Faye and Gomord 2010).

This study aimed to generate a tetravalent dengue antigen comprising all four serotypes by using a rice amylase 3D expression system and endoplasmic reticulum (ER) targeting. We show that when fused with the M-cell targeting ligand $\mathrm{Co} 1$ as the mucosal adjuvant, this plant-based dengue vaccine candidate was immunogenic following oral delivery in mice.

\section{Materials and methods}

\section{Construction of a binary vector encoding the tetravalent EDIII fusion Co1 gene}

The wild type and synthetic $t E D I I I$ genes described in the previous paper (So-Chon Han 2018) were amplified using Ex Taq polymerase (TaKaRa, Korea) for fusion to M-cell ligand peptide (Co1, 12 aa) or further extension with ER targeting peptide (SEKDEL). The purified DNA fragment was subcloned into pGEM-T Easy vector and subsequently sequenced to confirm the correct sequence and in-frame gene (Cosmo Gene Tech, South Korea). The wild type $t E D I I I$ fused to Co1 ( $t E D I I I-C o 1)$ or synthetic tEDIII-Col (stEDIII-Col) was amplified with forward and reverse primer sets, Tetra1-F and tEDIII-Co1A(K)-R for wtEDIII-Col; stEDIII(B)-F and Co1A(K)-R for stEDIIICol (Table 1), respectively. Then, the plasmids digested by BamHI and KpnI of PCR product were cloned into a rice expression vector (So-Chon Han 2018), which contains two expression cassettes for foreign gene and selection marker in transgenic cells, yielding pMYV687 and pMYV690,

Table 1 List of primars to amplify Co1 fusion tEDIII genes and confirm the integrated genes using the genomic DNA PCR analysis

\begin{tabular}{ll}
\hline Primer name & Primer sequence $\left(5^{\prime}-3^{\prime}\right)$ \\
\hline Tertra 1-F & ggatccATGAAGGGGACGTCATAT \\
tEDIII-Co1A(K)-R & ggtaccTGGAAGTGGAGATCTAGCTGGAAG \\
& CTGATGAAAAGAAGAACTTCCTTTCTT \\
& GAA \\
stEDIII(B)-F & ggatccATGAAGGGAACT \\
Co1A(K)-R & ggtaccTGGAAGTGGAGA \\
\hline
\end{tabular}


respectively (Fig. 1a). For ER targeting of stEDIII-Col, the stEDIII-Col fragment digested by BamHI/KpnI was cloned into an intermediate rice expression vector pMYV800, which has ER retention peptide, SEKDEL, between KpnI and SacI restriction sites, generating pMYV804 (Fig. 1a).

\section{Transformation and regeneration}

To obtain the transgenic rice calli, the materials and cultivation protocol was as described in the previous paper (SoChon Han 2018). Briefly, the embryogenic calli induced from the sterilized rice seeds (Oryza sativa L. cv. Dongin) were collected and transformed via a biolistic particle delivery system. The putative transgenic single cells were picked and propagated on the callus induction medium containing $50 \mathrm{mg} / \mathrm{L}$ of hygromycin B. For the development of transgenic calli shoots, the selected rice calli were incubated on Cambia medium supplemented with N6 salts with vitamins, sucrose $(30 \mathrm{~g} / \mathrm{L})$, proline $(0.5 \mathrm{~g} / \mathrm{L})$, glutamine $(0.5 \mathrm{~g} / \mathrm{L})$ casein enzymatic hydrolysate $(0.3 \mathrm{~g} / \mathrm{L})$, NAA $(0.5 \mathrm{mg} / \mathrm{L})$, BAP (3 mg/L) and hygromycin B $(50 \mathrm{mg} / \mathrm{l})$. MS basal medium plus Gelrite $(2 \mathrm{~g} / \mathrm{L})$ was used to stimulate rooting.

\section{Analysis of the integration and transcription of target genes}

To screen the transformed lines, genomic DNA PCR amplification and Northern blotting were performed as described previously (So-Chon Han 2018). Briefly, the genomic DNA extracted from non-transformed and transformed calli was amplified with gene-specific forward and reverse primers (Table 1) to verify the gene integration into the rice nuclear genome and total rRNA hybridized with $\alpha{ }^{-32} \mathrm{P}$-labeled (Promega, USA) tEDIII-Co1 or stEDIII-Co1 DNA fragment to detect mRNA expression.

(a)

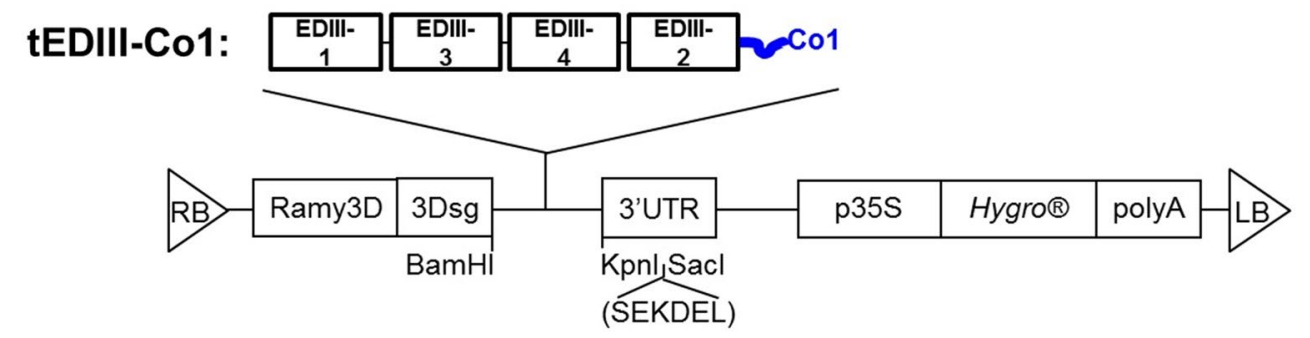

(b)

\begin{tabular}{cc}
\hline $\begin{array}{c}\text { Name of } \\
\text { plasmid }\end{array}$ & gene \\
\hline V687 & wild tEDIII-C01 (wtEDIII-Co1) \\
V690 & synthetic tEDIII-Co1 (stEDIII-Co1) \\
V804 & synthetic tEDIII-Co1 with SEKDEL (stEDIII-Co1 SEKDEL) \\
\hline
\end{tabular}
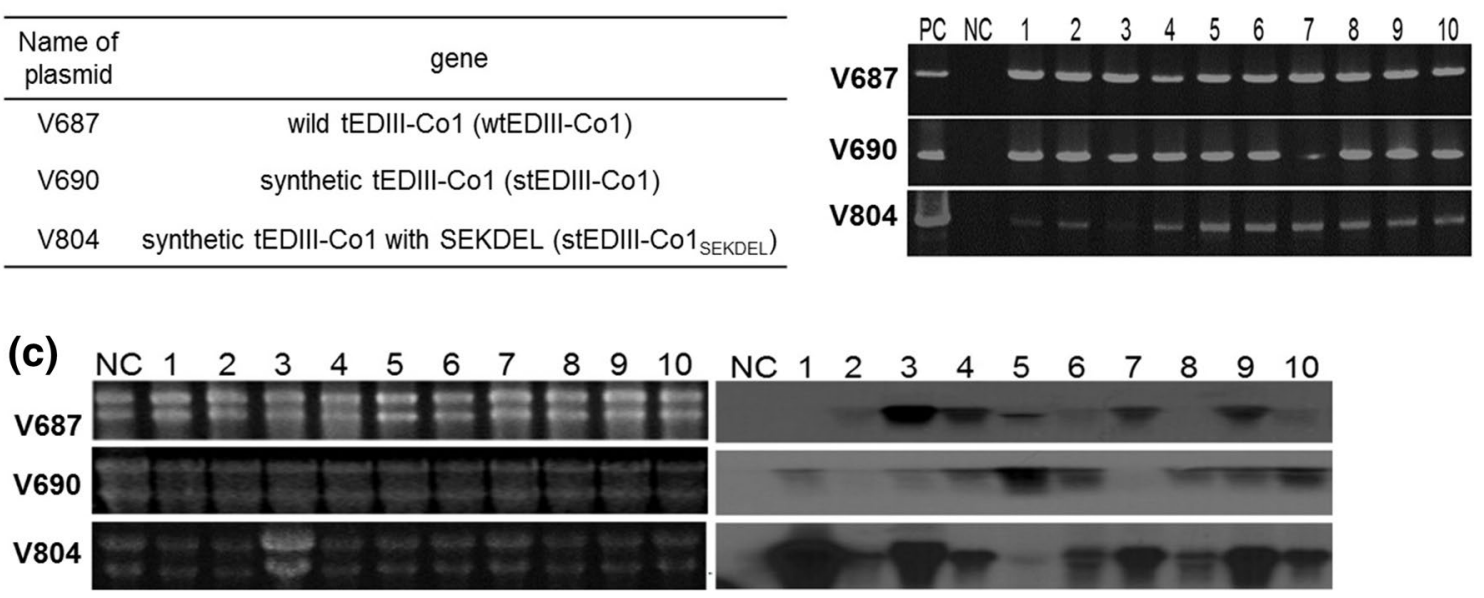

Fig. 1 Gene construction of tEDIII-Co1 and selection of transgenic cell lines by genomic DNA PCR and Northern blot analyses. a The wild type or synthesized tEDIII fused to Co1 gene constructed into a binary vector containing two expression cassettes: rice amylase 3D promoter (Ramy3D) - 3D signal peptide sequence (3Dsg) - 3' untranslated region (UTR); 35S promoter (p35S)-hygromycin resistant gene (Hygroß)—-polyA terminator (polyA). SEKDEL peptide sequence was inserted between $\mathrm{KpnI}$ and SacI restriction sites within a binary vector for ER retention of tEDIII-Co1. b The gene integration of tEDIII-Co1 was confirmed by genomic DNA PCR analysis and the $1.3 \mathrm{~kb}$ DNA fragment corresponding to tEDIII-Co1 detected in transgenic lines. c Total rRNA was fractionated on $1.2 \%$ formaldehyde-containing agarose gels (left) and the mRNA expression of tEDIII-Co1 was detected in the transgenic cells (right). PC, tEDIII-Co1 DNA amplified with plasmid used as positive control in PCR analysis. NC, the genomic DNA or rRNA extracted from nontransformed rice callus used as negative control in PCR or Norther blot analysis, respectively. Lanes 1-10, the genomic DNA or rRNA extracted from transformed rice callus lines 


\section{Detection and quantification of antigen proteins}

For detection and quantification of the expressed protein, four transgenic lines showing a strong mRNA expression of each gene construct were selected and lyophilized for further experiments. Total soluble protein (TSP) was extracted with a protein extraction buffer $(200 \mathrm{mM}$ Tris- $\mathrm{HCl}, \mathrm{pH} 8.0$, $100 \mathrm{mM} \mathrm{NaCl}, 400 \mathrm{mM}$ sucrose, $10 \mathrm{mM}$ EDTA, $14 \mathrm{mM}$ 2-mercaptoethanol, $1 \mathrm{mM}$ phenylmethylsulfonyl fluoride (PMSF), and $0.05 \%$ Tween 20) and used for Western blot analysis after probing by anti-dengue monoclonal antibody (Serotech, UK). TSP of non-transformed callus was used as the negative control in this study. The protocol for generating recombinant tEDIII or cEDIII and the immunoblot analysis was described previously (Kim et al. 2016, So-Chon Han 2018). To measure the amount of tEDIII-Co1 protein produced by each construct, indirect enzyme-linked immunosorbent assay (ELISA) was conducted. Briefly, $3 \mu \mathrm{g} / \mathrm{mL}$ of TSP was loaded in the top wells of a 96-well microtiter plate (NUNC, USA) following two-fold serial dilution in bicarbonate buffer ( $15 \mathrm{mM} \mathrm{Na}_{2} \mathrm{CO}_{3}$ and $35 \mathrm{mM} \mathrm{NaHCO}_{3}$ ), $\mathrm{pH} 9.6$ and then coated overnight at $4{ }^{\circ} \mathrm{C}$. The wells were blocked by adding $300 \mu \mathrm{L} /$ well of $1 \%$ bovine serum albumin (BSA) in PBS and incubating at $37{ }^{\circ} \mathrm{C}$ for $2 \mathrm{~h}$, followed by three washes using PBST buffer (PBS containing $0.05 \%$ Tween 20). The wells were loaded with $100 \mu \mathrm{L} /$ well of a 1:2000 dilution of mouse anti-dengue antibody (Serotech, UK), and incubated for $2 \mathrm{~h}$ at $37^{\circ} \mathrm{C}$, followed by washing three times with PBST buffer. The plate was then incubated with $100 \mu \mathrm{L} /$ well of the secondary antibody, a 1:7000 dilution of anti-mouse IgG conjugated with alkaline phosphatase (Sigma-Aldrich, USA) for $2 \mathrm{~h}$ at $37^{\circ} \mathrm{C}$ and washed three times with PBST buffer. The Optical density (OD) was measured at $405 \mathrm{~nm}$ in an ELISA reader (Tecan, Austria) after $15 \mathrm{~min}$ incubation with $100 \mu \mathrm{L} /$ well of phosphatase substrate (Sigma-Aldrich, USA).

\section{Oral immunization}

The 6 weeks old Balb/c female mice were purchased from Charles River Laboratories through Orient Bio, Inc. (Sungnam, Korea) and maintained under general specific pathogen-free conditions. The experimental procedures involving laboratory animals was approved by the Institutional Animal Care and Use Committee of the Chonbuk National University (Approval Number: CBU 2013-1-0021). One hundred $\mu \mathrm{g}$ of tEDIII-Co $1_{\text {SEKDEL }}$ protein was administered orally to mice with or without $10 \mu \mathrm{g}$ of Cholera Toxin (sigma, USA) or $2.5 \mathrm{mg}$ of Saponin Quillaja sp (Sigma, USA). For oral delivery, a total of $500 \mathrm{mg}$ of dried rice cells, either wild type or producing tEDIII-Co1, was suspended in $500 \mu \mathrm{L}$ of PBS buffer and administrated by gavage needle to five mice in each group. Equal amount of non-transgenic lyophilized rice cells was used as a control. Oral administration was performed at weeks 0,2 , and 4 , and serum and feces from the immunized mice collected 4 days later to analyze the antigen specific antibody induction as depicted in Fig. 3b. Before culling the mice, $100 \mu \mathrm{g}$ of bacterial tEDIII-Co1 protein formulated with $100 \mu \mathrm{L}$ of incomplete Freund's adjuvant was injected subcutaneously to test for immune tolerance.

\section{Analysis of antibody induction}

To test the antibody induction in immunized sera or feces, the recombinant tEDIII protein $(80 \mathrm{ng} /$ well) was coated and ELISA performed as described above. 1:200 of serum or 1:10 dilution of fecal extracts were used as the starting concentration and diluted serially. Alkaline phosphatase (AP) conjugated anti- mouse IgG or IgA (Sigma, USA) was used as the detection antibody. For serotype specific cross-reactivity assay, E. coli-produced EDIII protein representing each serotype (1-4) was used.

\section{Analyses of lymphocytes by ELISPOT (enzyme-linked immunosorbent spot) and proliferation assay}

The splenocytes isolated from the immunized mice were used to measure the number of IgG-secreting cells (SCs) by ELISPOT or to perform lymphocyte proliferation assays as described previously (Kim et al. 2016). Briefly, for ELISPOT assay, the recombinant tEDIII antigen protein was precoated onto the cellulose ester membrane-lined microtiter plates (Millipore, USA) overnight at $4{ }^{\circ} \mathrm{C}$ and incubated with the isolated lymphocytes for $36 \mathrm{~h}$ at $37^{\circ} \mathrm{C}$. The cells were then washed and incubated with alkaline phosphatase (AP) conjugated anti-IgG antibody and reaction developed using the BICP/NBT reagent. The spots were counted under a microscope and the mean number of spots from the triplicates for each dilution was calculated. The tEDIII-specific lymphocyte proliferation assay was performed by ${ }^{3}[\mathrm{H}]$-thymidine incorporation assay as described previously (Kim et al. 2016). Stimulation indices were calculated by dividing the tritium incorporation (cpm) in cells treated with tEDIII by that induced by medium alone.

\section{Statistical analysis}

Five animals were used per group for immunization experiments. All ELISA assays were performed in triplicates and the values (from a representative experiment of typically three performed) are shown as the mean +/- standard deviation. For cellular response assay, $t$-test was used to determine statistically significant differences. Exell Microsoft and GraphPad Prism v.7.04 software used for statistical analysis. 


\section{Results}

\section{Construction of a binary vector encoding the tetravalent EDIII fusion Co1 gene}

A single chain tetrameric EDIII ( $t E D I I I)$ covering the all four serotypes has been generated and fused to Co1 peptide (SFHQLPARSPLP) which is a known mucosal adjuvant (Kim et al. 2010). For the extension of $t E D I I I$ with Co1 at the carboxyl-terminus, a plant codon optimized Co1 was designed for in-frame fusion and synthesized using tEDIIICo1A(K)-R reverse primer (Table 1). Co1 was added to a wild type or synthetic $t E D I I I$ by PCR amplification and cloning into a binary vector harboring rice 3D amylase promoter with its signal sequence at the upstream and amylase 3' UTR at the downstream to control an expression of a foreign gene. A strong promoter (Ramy3D) combining with plant codon optimization and/or targeting to subcellular localization (ER) was employed to achieve improved production of tEDIII-Co1 in this study.

\section{Integration and transcription of target genes}

Three constructs including pMYV687, pMYV690 and pMYV804 were used to transform rice embryogenic calli and gene integration into the nuclear genome and mRNA expression verified by DNA PCR and Northern blot analyses, respectively. $1.3 \mathrm{~kb}$ PCR fragment corresponding to $t E D I I I-C o l$ was detected in the putative transgenic cell lines, as shown in Fig. 1b, but not in the negative control. Most of the cell lines growing in the hygromycin medium had detectable mRNA expression with somewhat stronger expression detected for synthetic than the wild type gene (Fig. 1c).

\section{Expression of tEDIII-Co1 fusion protein}

Four strongest mRNA expressing cell lines were subjected to analysis by anti-dengue monoclonal antibody under reducing

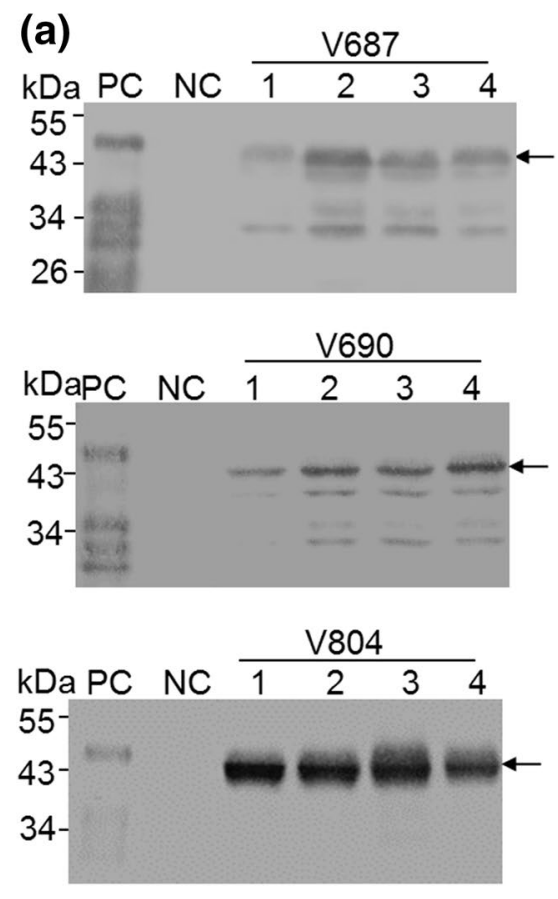

Fig. 2 Detection of tEDIII-Co1 by Western blot analysis. a Protein extracts transformed with each construct were analysed to detect tEDIII-Co1 fusion protein. Immunoblotting was performed under reducing (a) or non-reducing (b and $\mathbf{c}$ ) condition and probing by anti-dengue monoclonal antibodies. The expected size of $47 \mathrm{kDa}$ was detected in all constructs although some truncated fragments were detected in secreted (top and middle) but not ER-targeted protein (bottom). b The tEDIII-Co1 cell line showing the highest expression was selected for propagation. $30 \mu \mathrm{g}$ of total soluble proteins containing tEDIII (lane 1) or tEDIII-Co1 (lane 2) were separated on $12 \%$ acrylamide gel (left) and analysed by Western blotting (right) - lane 1: tEDIII; lane 2, tEDIII-Co1. c The dried calli expressing tEDIII (synthesized by plasmid pMYV698) and the two tEDIII-Co1 constructs (synthesized by pMYV690 and pMYV804) were analyzed by Western blotting following 1 year storage at $-70{ }^{\circ} \mathrm{C} ; 10 \mu \mathrm{L}$ and $20 \mu \mathrm{L}$ of TSP loaded in lane 1 and lane 2, respectively. Recombinant tEDIII-Co1 or EDIII protein produced in E. coli were used as the positive control (Lane PC) and non-transformed rice callus as the negative control (Lane NC) in (a), (b), and (c). Lanes 1-4 in (a) represent the transgenic cell lines producing tEDIII-Co1 fusion proteins synthesized by the plasmids pMYV687, pMYV690 and pMYV804, respectively. Molecular weight markers $(\mathrm{M})$ in $\mathrm{kDa}$ are shown on the left of each panel 
(Fig. 2a) or non-reducing (Fig. 2b, c). The main protein band at $47 \mathrm{kDa}$ corresponding to tEDIII-Co1 and some truncated bands appeared in the rice cell lines transformed with constructs pMYV687 (wild type) and pMYV690 (synthetic). Similarly, the recombinant tEDIII-Co1 produced in E. coli appeared as one dominant and a couple of smaller bands - the slightly higher molecular weight of the main expression product than the plant-expressed protein due to the presence of the N-terminal His tag. However, tEDIIICo1 $1_{\text {SEKDEL }}$ (transformed with pMYV804) appeared as a single band with increased stability (Fig. 2a, bottom panel). No protein was detected in non-transgenic cells for any of the constructs. This result indicates that the higher expression of intact protein is dependent on ER targeting more than codon optimization. The tEDIII-Co1 fusion protein was slightly bigger than the tEDIII alone (Fig. 2b, right panel) due to the presence of Co1 peptide $(1.3 \mathrm{kDa})$. The size of the fusion protein was calculated using the ProParam tool (https://www.expasy.org/proteomics). The quantity of proteins was determined by densitometric analysis of immunoblots by comparing to the known amounts of the bacterial EDIII as described previously (So-Chon Han 2018). The results showed that $\mathrm{tEDIII-Co1_{ \text {SEKDEL } }}$ (V804) expressed 2.4 times higher than tEDIII-Co1 (V690), with TSP estimated to be $3.6 \%$ and $1.5 \%$, respectively. However, similar to our previous studies with ER-targeted tEDIII (V698) (So-Chon Han 2018), the transgenic cells, when lyophilized and stored at $-70{ }^{\circ} \mathrm{C}$ for 1 year showed stable expression of tEDIIICo1 (V804)] only when ER-targeted, while in the absence of ER targeting (V690) the expression significantly decreased (Fig. 2c). The amount of tEDIII-Co1 ${ }_{\text {SEKDEL }}$ (V804) was determined to be $316.7 \mu \mathrm{g}$ per gram of dry weight, which was sufficiently high to be feasible for mouse oral studies.

\section{Oral immunogenicity of tEDIII-Co1 fusion protein}

Sera and fecal extracts from mice immunized three times with tEDIII-Co1 alone showed antigen specific-IgG and IgA responses, respectively, (Fig. 3b). Combining with $\mathrm{CT}$ or saponin generally did not significantly enhance the mean responses but somewhat reduced variations between individual mice, at either 2 or 4 weeks after the final immunisation. Therefore, neither adjuvant gave significant advantage over Co1 fusion protein alone. Mock immunised mice did not show any antigen specific antibodies. Orally administered tEDIII-Co1 induced a balanced Th1/2 response as indicated by high titre of IgG1 (Th2) and IgG2a and IgG2b (Th1) antibody subtypes (Fig. 3c). (a)

\begin{tabular}{cc}
\hline \multicolumn{2}{c}{ group } \\
antigen & adjuvant \\
\hline WT: mock & - \\
tEDIII-Co1 & - \\
tEDIII-Co1 & CT \\
tEDIII-Co1 & SP \\
\hline
\end{tabular}

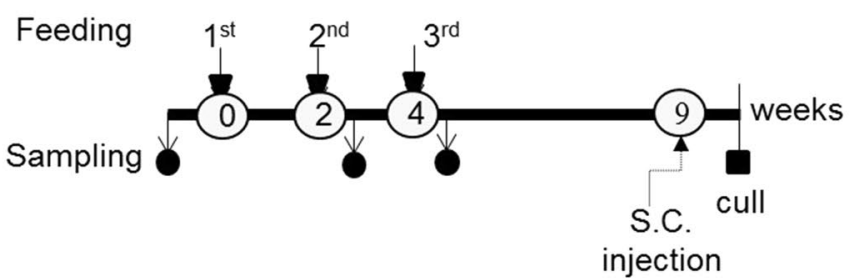

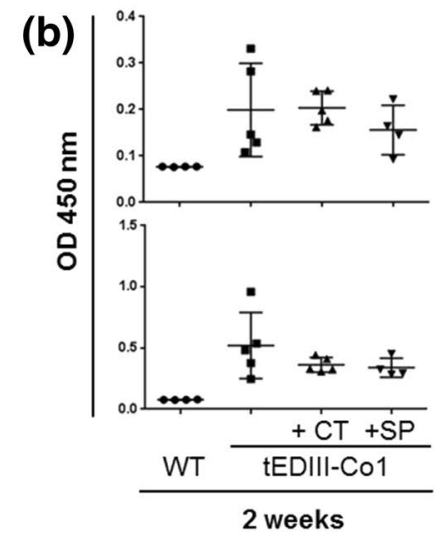

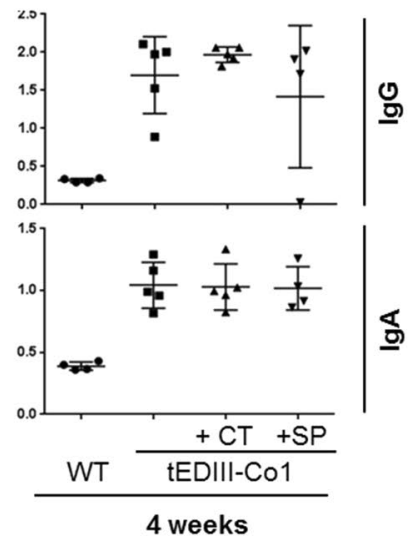

Fig. 3 Oral immunization and antibody responses in sera and feces. a Dried cells containing $100 \mu \mathrm{g}$ of tEDIII-Co1 were gavaged to mice. Four groups including non-transgenic dried cells (WT), tEDIII-Co1 with/without additional adjuvants such as cholera toxin (CT) or sapo$\operatorname{nin}(\mathrm{SP})$ were tested. Three oral administrations to test oral immuno-

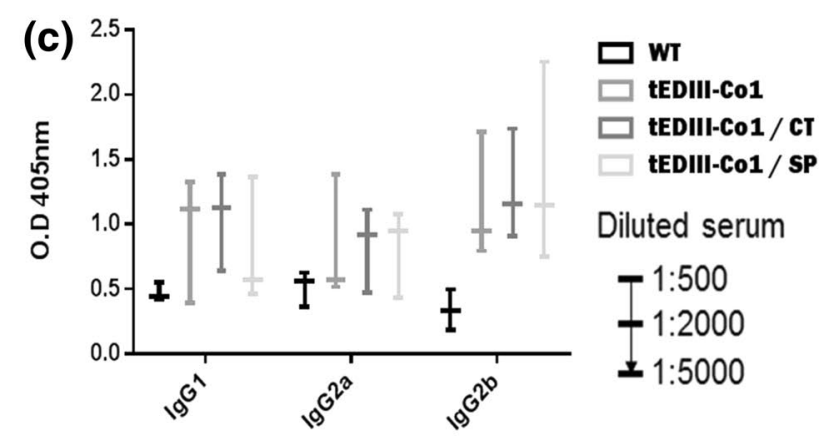

genicity and then a subcutaneous injection 5 weeks later to confirm overcoming oral tolerance, were performed (right). b Antigen specific $\mathrm{IgG}$ (sera) or IgA (feces) responses, c IgG1, IgG2a and IgG2b subtype responses in pooled sera of immunized mice detected in different serum dilutions 


\section{Reactivity of IgG antibodies and antigen-specific B and $T$ cells}

The IgG antibodies induced by tEDIII-Co1 in all groups could react to each serotype specific EDIII antigen and so could be expected to protect against all four serotypes
(Fig. 4). Successful oral priming and overcoming of the immunological tolerance was also demonstrated by a 'remote' subcutaneous injection (5 weeks later) that was still capable of boosting the antibody response, as shown in Fig. 5a. Furthermore, antigen-specific B and T cells could be detected in splenocytes from tEDIII-Co1 but not mock immunised mice (Fig. 5).
Fig. 4 Serotype specificity of the induced antibody response. ELISA plates were coated with EDIII derived from each DENV serotype and probed using twofold serial dilutions of pooled sera collected from immunized mice; a commercial monoclonal antibody (mAb 1-11, Serotec) was used as an internal positive control for the ELISA
Sero-1

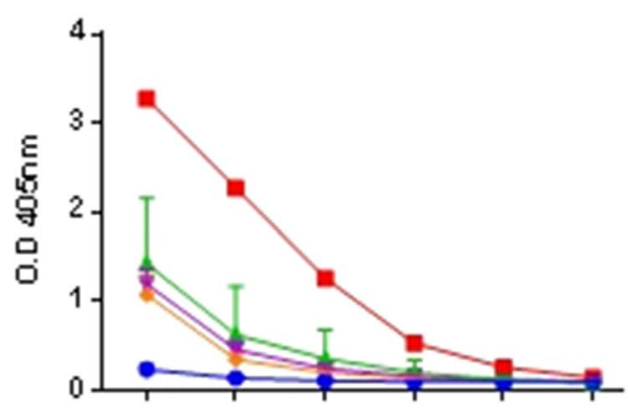

Sero-3

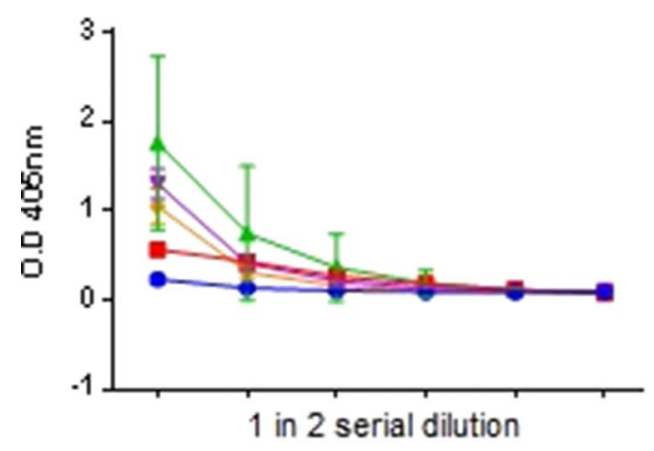

\$WT 中 MAb 中 tEDII-CO1 \& tEDII-CO1/CT \& tEDII-CO1/SP
Sero-2

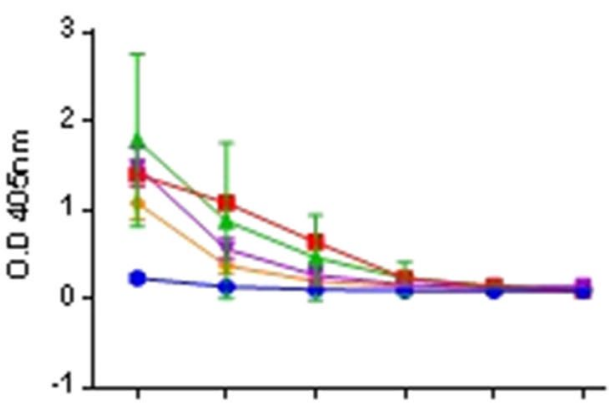

Sero-4

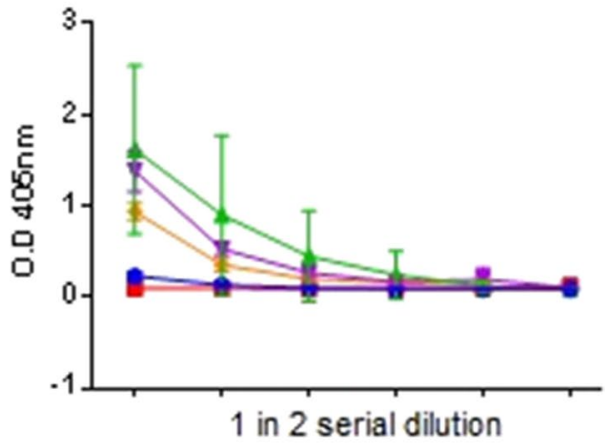

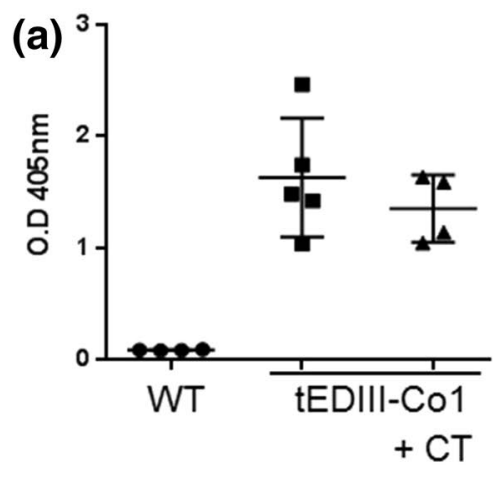

(b)

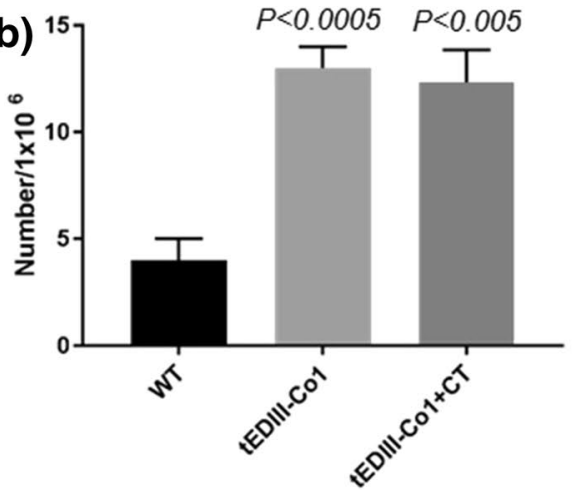

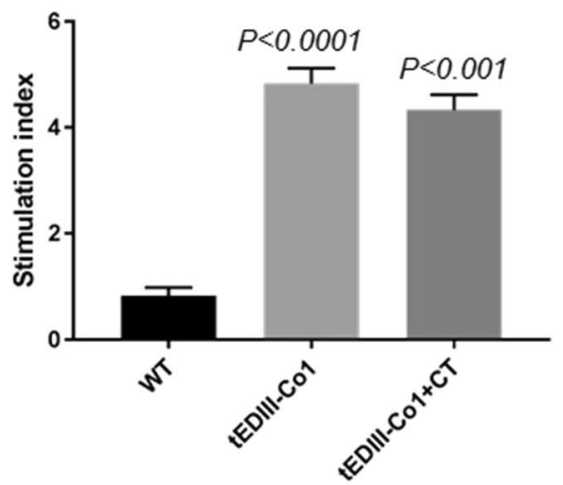

Fig. 5 Test for oral tolerance and splenic lymphocyte responses in immunized mice. a The IgG antibody showed after subcutaneous injection with recombinant tEDIII protein in the immunized group with tEDIII-Co1 W/O CT adjuvant and the test for oral tolerance confirmed. b B cell ELISPOT, showing the mean number of antibody- secreting cells from triplicate cultures; WT induced low frequency antibody-secreting cells but tEDIII-Co1 induced a statistically significant increase (middle). $\mathrm{T}$ cell proliferation measured by $3[\mathrm{H}]$-thymidine incorporation and presented as the stimulation indices (right) 


\section{Discussion}

The fastest growing human arboviral disease, dengue, has become a global life-threatening public health concern, with 2.5 billion individuals in more than 100 countries at risk of infection (Brady et al. 2012). To reduce this threat, new antiviral drugs, better vector (mosquito) control and development of an efficient and affordable dengue vaccine are all needed (Hasan et al. 2016). However, the existence of four antigenically different serotypes (DEN-1, DEN-2, DEN-3, and DEN-4) of dengue virus makes the latter task very difficult and complex. Natural immunity to dengue virus infection elicits long-lasting protection only to the same serotype and only short-term (months) protection against other serotypes. Furthermore, severe cases such as dengue hemorrhagic fever (DHF) and dengue shock syndrome (DSS) can develop by sequential infection with different dengue virus serotypes (Halstead 1988; Kurane 2007; Snow et al. 2014). It is for this reason that the WHO strongly recommends that the new dengue vaccine (Dengvaxia ${ }^{\circledR}$ ) is given only to people who were previously infected, since giving it to unexposed young children under the age of 9 could lead to more severe subsequent infections (Hadinegoro et al. 2015).

Most of the leading vaccine candidates are formulated with four live-attenuated viruses (Pang and Loh 2017), requiring multiple-dose immunization regimens (Kanesathasan et al. 2001). Therefore, more effort and diverse approaches are required to identify the most promising dengue vaccination strategy. This almost certainly will require detailed scrutiny and comparisons of vaccineinduced immune responses to those induced in natural infection. Different types of vaccine candidates may need to be considered including the so-called 'self-adjuvanting' subunit vaccines, for safety and cost-effectiveness reasons. We reported previously on one such vaccine candidate, a multimeric IgG Fc fusion protein targeting antigen presenting cells and inducing high-level humoral and cellular immune responses (Kim et al. 2018a, 2017). The others include the modified immune complex platform (Kim et al. 2015) and cholera toxin B subunit fusion constructs (Kim et al. 2016). An alternative strategy based on targeting the gut microfold (M) cells was explored in this study is. M cells have an important role in antigen sampling without degradation, which can facilitate antigen-specific immune responses (Cerutti and Rescigno 2008). Kim et al. (2010) isolated the $\mathrm{M}$ cell-specific peptide ligands (identified as $\mathrm{Co} 1, \mathrm{Co} 2$ and $\mathrm{Co} 3$ ) and characterized the function of $\mathrm{Co} 1$ as a ligand for complement $\mathrm{C} 5$ a receptors expressed on $\mathrm{M}$ cells, thus having a mucosal adjuvant activity (Kim et al. 2010). They demonstrated the uptake of Co1 fusion antigen protein (produced in E. coli) by M cells and induction of antigen-specific B and T cells after mucosal vaccination (Kim et al. 2018b, 2010). More recently, we demonstrated the immunogenic potential of two types of tetravalent dengue vaccine candidates (cEDIII-Co1 and Tet-EDIIICo1) expressed in plant and yeast cells, respectively (Kim et al. 2013; Nguyen et al. 2015). Furthermore, we and others also tested an animal vaccine candidate based on Co1 fusion with porcine epidemic diarrhoea virus (PEDV) antigens and expressed in transgenic rice or lactobacillus bacteria (Huy et al. 2012; Ma et al. 2018). These studies highlighted the potential application of $\mathrm{C} 5 \mathrm{a}$ receptor as a target for mucosal vaccines.

The major target for antibody and $\mathrm{T}$ cell responses against flaviviruses such as dengue virus is the envelope (E) protein. In comparison, non-structural (NS) protein 2 is predominantly the target for $\mathrm{T}$ cell responses and only a weak antibody response, while NS3 induces only T cell response (Rothman 2004). E domain III of dengue virus is a suitable vaccine target because it is involved in the host cell receptor-binding, can induce neutralizing antibodies and is implicated in the pathogenesis of DHF/DSS. However, EDIII has only a very low intrinsic potential for inducing protective antibodies (Chin et al. 2007; Crill and Roehrig 2001; Simmons et al. 2001, 1998). Etemad et al. (2008) generated the tetravalent chimeric EDIII protein derived from four DEN virus serotypes in Pichia pastoris and the purified protein elicited neutralizing antibodies against all four serotypes after intraperitoneal injection with different adjuvants (Etemad et al. 2008). In the present study, oral delivery of crude rice cells expressing tetrameric EDIII-Co1 protein within the ER compartment induced systemic and mucosal immune responses to the dengue antigen. This is the proofof-principle of the feasibility of this approach to develop a cheap and safe vaccine that does not require an exogenous adjuvant. The utility of the $\mathrm{M}$ cell targeting by incorporation of the Co1 peptide was underscored by the absence of an immune response by the orally administered tEDIII alone in our previous (unpublished) studies.

In summary, a single tetravalent dengue antigen polypeptide fused to M-cell target ligand (tEDIII-Col) and expressed in transgenic rice cells showed to be a promising oral vaccine candidate. ER targeting (SEKDEL) showed to confer a superior stability and slightly enhanced expression profile compared to the secreted protein. Only $100 \mu \mathrm{g}$ of tEDIII fused to Co1 was sufficient to induce both systemic IgG and mucosal IgA antibodies and circumvent oral tolerance. We therefore conclude that this simple tetravalent dengue fusion protein with Co1 could be exploited as an alternative subunit dengue vaccine strategy to complement the existing vaccine approaches.

Acknowledgements This study was supported by NRF2014K1B1A1073861 through the National Research Foundation (NRF) 
funded by the Korean Ministry of Science, ICT \& Future Planning, Republic of Korea.

Author Contributions M-Y K. conceived and designed the overall study. M-Y K. and B-Y K performed the experiments and co-wrote the manuscript.

\section{Compliance with ethical standards}

Conflict of interest The authors declare no conflict of interest.

\section{References}

Bhatt S, Gething PW, Brady OJ, Messina JP, Farlow AW, Moyes CL, Drake JM, Brownstein JS, Hoen AG, Sankoh O, Myers MF, George DB, Jaenisch T, Wint GR, Simmons CP, Scott TW, Farrar JJ, Hay SI (2013) The global distribution and burden of dengue. Nature 496(7446):504-507. https://doi.org/10.1038/nature12060

Brady OJ, Gething PW, Bhatt S, Messina JP, Brownstein JS, Hoen AG, Moyes CL, Farlow AW, Scott TW, Hay SI (2012) Refining the global spatial limits of dengue virus transmission by evidencebased consensus. PLoS Negl Trop Dis 6(8):e1760. https://doi. org/10.1371/journal.pntd.0001760

Cerutti A, Rescigno M (2008) The biology of intestinal immunoglobulin A responses. Immunity 28(6):740-750. https://doi. org/10.1016/j.immuni.2008.05.001

Chan HT, Daniell H (2015) Plant-made oral vaccines against human infectious diseases-Are we there yet? Plant Biotechnol J 13(8):1056-1070. https://doi.org/10.1111/pbi.12471

Chin JF, Chu JJ, Ng ML (2007) The envelope glycoprotein domain III of dengue virus serotypes 1 and 2 inhibit virus entry. Microbes Infect 9(1):1-6. https://doi.org/10.1016/j.micinf.2006.09.009

Crill WD, Roehrig JT (2001) Monoclonal antibodies that bind to domain III of dengue virus E glycoprotein are the most efficient blockers of virus adsorption to Vero cells. J Virol 75(16):77697773. https://doi.org/10.1128/JVI.75.16.7769-7773.2001

Daniell H (2006) Production of biopharmaceuticals and vaccines in plants via the chloroplast genome. Biotechnol J 1(10):1071-1079. https://doi.org/10.1002/biot.200600145

Etemad B, Batra G, Raut R, Dahiya S, Khanam S, Swaminathan S, Khanna N (2008) An envelope domain III-based chimeric antigen produced in Pichia pastoris elicits neutralizing antibodies against all four dengue virus serotypes. Am J Trop Med Hyg 79(3):353-363

Faye L, Gomord V (2010) Success stories in molecular farming-a brief overview. Plant Biotechnol J 8(5):525-528. https://doi.org/10.11 11/j.1467-7652.2010.00521.x

Gonzalez-Rabade N, McGowan EG, Zhou F, McCabe MS, Bock R, Dix PJ, Gray JC, Ma JK (2011) Immunogenicity of chloroplast-derived HIV-1 p24 and a p24-Nef fusion protein following subcutaneous and oral administration in mice. Plant Biotechnol J 9(6):629-638. https://doi.org/10.1111/j.1467-7652.2011.00609.x

Hadinegoro SR, Arredondo-Garcia JL, Capeding MR, Deseda C, Chotpitayasunondh T, Dietze R, Muhammad Ismail HI, Reynales $\mathrm{H}$, Limkittikul K, Rivera-Medina DM, Tran HN, Bouckenooghe A, Chansinghakul D, Cortes M, Fanouillere K, Forrat R, Frago C, Gailhardou S, Jackson N, Noriega F, Plennevaux E, Wartel TA, Zambrano B, Saville M (2015) Efficacy and long-term safety of a dengue vaccine in regions of endemic disease. $\mathrm{N}$ Engl $\mathrm{J}$ Med 373(13):1195-1206. https://doi.org/10.1056/NEJMoa1506223

Halstead SB (1988) Pathogenesis of dengue: challenges to molecular biology. Science 239(4839):476-481
Hasan S, Jamdar SF, Alalowi M, Al Ageel Al Beaiji SM (2016) Dengue virus: a global human threat: review of literature. J Int Soc Prev Community Dent 6(1):1-6. https://doi.org/10.4103/22310762.175416

Huy NX, Kim MY (2017) Overexpression and oral immunogenicity of a dengue antigen transiently expressed in Nicotiana benthamiana. Plant Cell Tiss Org 131(3):567-577. https://doi.org/10.1007/ s11240-017-1306-4

Huy NX, Kim SH, Yang MS, Kim TG (2012) Immunogenicity of a neutralizing epitope from porcine epidemic diarrhea virus: $M$ cell targeting ligand fusion protein expressed in transgenic rice calli. Plant Cell Rep 31(10):1933-1942. https://doi.org/10.1007/s0029 9-012-1306-0

Kanesa-thasan N, Sun W, Kim-Ahn G, Van Albert S, Putnak JR, King A, Raengsakulsrach B, Christ-Schmidt H, Gilson K, Zahradnik JM, Vaughn DW, Innis BL, Saluzzo JF, Hoke CH Jr (2001) Safety and immunogenicity of attenuated dengue virus vaccines (Aventis Pasteur) in human volunteers. Vaccine 19(23-24):3179-3188

Kim SH, Seo KW, Kim J, Lee KY, Jang YS (2010) The M cell-targeting ligand promotes antigen delivery and induces antigenspecific immune responses in mucosal vaccination. J Immunol 185(10):5787-5795

Kim TG, Kim MY, Huy NX, Kim SH, Yang MS (2013) M cell-targeting ligand and consensus dengue virus envelope protein domain III fusion protein production in transgenic rice calli. Mol Biotechnol 54(3):880-887. https://doi.org/10.1007/s12033-012-9637-1

Kim MY, Reljic R, Kilbourne J, Ceballos-Olvera I, Yang MS, Reyesdel Valle J, Mason HS (2015) Novel vaccination approach for dengue infection based on recombinant immune complex universal platform. Vaccine 33(15):1830-1838. https://doi.org/10.1016/j. vaccine.2015.02.036

Kim MY, Kim BY, Oh SM, Reljic R, Jang YS, Yang MS (2016) Oral immunisation of mice with transgenic rice calli expressing cholera toxin B subunit fused to consensus dengue cEDIII antigen induces antibodies to all four dengue serotypes. Plant Mol Biol 92(3):347-356. https://doi.org/10.1007/s11103-016-0517-0

Kim MY, Van Dolleweerd C, Copland A, Paul MJ, Hofmann S, Webster GR, Julik E, Ceballos-Olvera I, Reyes-Del Valle J, Yang MS, Jang YS, Reljic R, Ma JK (2017) Molecular engineering and plant expression of an immunoglobulin heavy chain scaffold for delivery of a dengue vaccine candidate. Plant Biotechnol J 15(12):1590-1601. https://doi.org/10.1111/pbi.12741

Kim MY, Copland A, Nayak K, Chandele A, Ahmed MS, Zhang Q, Diogo GR, Paul MJ, Hofmann S, Yang MS, Jang YS, Ma JK, Reljic R (2018a) Plant-expressed Fc-fusion protein tetravalent dengue vaccine with inherent adjuvant properties. Plant Biotechnol J 16(7):1283-1294. https://doi.org/10.1111/pbi.12869

Kim SH, Kim YN, Kim J, Jang YS (2018b) C5a receptor targeting of partial non-structural protein 3 of dengue virus promotes antigenspecific IFN-gamma-producing T-cell responses in a mucosal dengue vaccine model. Cell Immunol 325:41-47. https://doi. org/10.1016/j.cellimm.2018.01.016

Kurane I (2007) Dengue hemorrhagic fever with special emphasis on immunopathogenesis. Comp Immunol Microbiol Infect Dis 30(5-6):329-340. https://doi.org/10.1016/j.cimid.2007.05.010

Lee JH, Ko K (2017) Production of Recombinant Anti-Cancer Vaccines in Plants. Biomol Ther (Seoul) 25(4):345-353. https://doi. org/10.4062/biomolther.2016.126

Lee NH, Lee JA, Park SY, Song CS, Choi IS, Lee JB (2012) A review of vaccine development and research for industry animals in Korea. Clin Exp Vaccine Res 1(1):18-34. https://doi.org/10.7774/ cevr.2012.1.1.18

Ma S, Wang L, Huang X, Wang X, Chen S, Shi W, Qiao X, Jiang Y, Tang L, Xu Y, Li Y (2018) Oral recombinant Lactobacillus vaccine targeting the intestinal microfold cells and dendritic cells for delivering the core neutralizing epitope of porcine epidemic 
diarrhea virus. Microb Cell Fact 17(1):20. https://doi.org/10.1186/ s12934-018-0861-7

Mangold KA, Reynolds SL (2013) A review of dengue fever: a resurging tropical disease. Pediatr Emerg Care 29(5):665-669. https:// doi.org/10.1097/PEC.0b013e31828ed30e quiz 670-1

Minor PD (2015) Live attenuated vaccines: Historical successes and current challenges. Virology 479-480:379-392. https://doi. org/10.1016/j.virol.2015.03.032

Nguyen NL, So KK, Kim JM, Kim SH, Jang YS, Yang MS, Kim DH (2015) Expression and characterization of an M cell-specific ligand-fused dengue virus tetravalent epitope using Saccharomyces cerevisiae. J Biosci Bioeng 119(1):19-27. https://doi. org/10.1016/j.jbiosc.2014.06.005

Pang EL, Loh HS (2017) Towards development of a universal dengue vaccine - How close are we? Asian Pac J Trop Med 10(3):220 228. https://doi.org/10.1016/j.apjtm.2017.03.003

Rodriguez-Barraquer I, Cordeiro MT, Braga C, de Souza WV, Marques ET, Cummings DA (2011) From re-emergence to hyperendemicity: the natural history of the dengue epidemic in Brazil. PLoS Negl Trop Dis 5(1):e935. https://doi.org/10.1371/journ al.pntd.0000935

Rothman AL (2004) Dengue: defining protective versus pathologic immunity. J Clin Invest 113(7):946-951. https://doi.org/10.1172/ JCI21512

Shin YJ, Hong SY, Kwon TH, Jang YS, Yang MS (2003) High level of expression of recombinant human granulocyte-macrophage colony stimulating factor in transgenic rice cell suspension culture.
Biotechnol Bioeng 82(7):778-783. https://doi.org/10.1002/ bit.10635

Simmons M, Nelson WM, Wu SJ, Hayes CG (1998) Evaluation of the protective efficacy of a recombinant dengue envelope $\mathrm{B}$ domain fusion protein against dengue 2 virus infection in mice. Am J Trop Med Hyg 58(5):655-662

Simmons M, Murphy GS, Hayes CG (2001) Short report: Antibody responses of mice immunized with a tetravalent dengue recombinant protein subunit vaccine. Am J Trop Med Hyg 65(2):159-161

Snow GE, Haaland B, Ooi EE, Gubler DJ (2014) Review article: research on dengue during World War II revisited. Am J Trop Med Hyg 91(6):1203-1217. https://doi.org/10.4269/ajtmh.14-0132

So-Chon Han N-XH, Mi-Young K (2018) Enhanced expression of dengue virus EDIII-based tetravalent antigen protein using transgenic rice callus. Plant Biotechnol Rep 12(3):207-215. https://doi. org/10.1007/s11816-018-0487-6

Yamamoto T, Hoshikawa K, Ezura K, Okazawa R, Fujita S, Takaoka M, Mason HS, Ezura H, Miura K (2018) Improvement of the transient expression system for production of recombinant proteins in plants. Sci Rep 8(1):4755. https://doi.org/10.1038/s4159 8-018-23024-y

Publisher's Note Springer Nature remains neutral with regard to jurisdictional claims in published maps and institutional affiliations. 